\title{
Tuberculosis and other bacterial co-infection in Cambodia: a single center retrospective cross-sectional study
}

Engi F. Attia ${ }^{1,2}$, Yaty Pho ${ }^{1,2}$, Somary Nhem³ ${ }^{3}$ Chandara Sok ${ }^{3}$, Borady By ${ }^{3}$, Dariven Phann ${ }^{3}$, Huy Nob ${ }^{1,2}$, Sovanndeth Thann ${ }^{3}$, Sinath Yin $^{3}$, Rachael Noce ${ }^{1,4}$, Chamrouensann Kim ${ }^{5}$, Joanne Letchford ${ }^{6}$, Thomas Fassier ${ }^{7}$, Sarin Chan ${ }^{7,8}$ and T. Eoin West ${ }^{1,2^{*}}$ (D)

\begin{abstract}
Background: Cambodia, a lower middle-income country of about 16 million individuals in southeast Asia, endures a high burden of both tuberculosis and other lower respiratory infections. Differentiating tuberculosis from other causes of respiratory infection has important clinical implications yet may be challenging to accomplish in the absence of diagnostic microbiology facilities. Furthermore, co-infection of tuberculosis with other bacterial lower respiratory infections may occur. The objective of this study was to determine the prevalence and etiologies of tuberculosis and other bacterial co-infection and to analyze the clinical and radiographic characteristics of patients presenting with respiratory infection to a provincial referral hospital in Cambodia.
\end{abstract}

Methods: We performed a retrospective, cross-sectional analysis of laboratory and clinical data, on patients presenting with respiratory symptoms to a chest clinic of a 260-bed provincial referral hospital in Cambodia. We analyzed mycobacterial and bacterial sputum test results, and demographics, medical history and chest radiography.

Results: Among 137 patients whose treating clinicians ordered sputum testing for tuberculosis and other bacteria, the median age was 52 years, 54\% were male, 3\% had HIV infection, and 26\% were current smokers. Nearly all had chronic respiratory symptoms (>96\%) and abnormal chest radiographs (87\%). Sputum testing was positive for tuberculosis in 40 patients (30\%) and for bacteria in 60 patients (44\%); 13 had tuberculosis and bacterial co-infection (9\% overall; $33 \%$ of tuberculosis patients). Clinical characteristics were generally similar across pulmonary infection types, although co-infection was identified in $43 \%$ of patients with one or more cavitary lesions on chest radiography. Among those with bacterial growth on sputum culture, Gram negative bacilli (Klebsiella and Pseudomonas spp.) were the most commonly isolated.

Conclusions: Among patients with symptoms of respiratory infections whose treating clinicians ordered sputum testing for tuberculosis and other bacteria, $9 \%$ of all patients and 33\% of tuberculosis patients had tuberculosis and bacterial co-infection. Greater availability of microbiologic diagnostics for pulmonary tuberculosis and bacterial infection is critical to ensure appropriate diagnosis and management.

Keywords: Lung, Pneumonia, Tuberculosis, Diagnostics, Respiratory infection, Cambodia

\footnotetext{
* Correspondence: tewest@uw.edu

${ }^{1}$ International Respiratory and Severe Illness Center, University of

Washington, Seattle, WA, USA

${ }^{2}$ Division of Pulmonary, Critical Care, and Sleep Medicine, Department of

Medicine, University of Washington, 325 Ninth Avenue, Box 359640, Seattle,

WA 98104, USA

Full list of author information is available at the end of the article
}

(c) The Author(s). 2019 Open Access This article is distributed under the terms of the Creative Commons Attribution 4.0 International License (http://creativecommons.org/licenses/by/4.0/) which permits unrestricted use, distribution, and reproduction in any medium, provided you give appropriate credit to the original author(s) and the source, provide a link to the Creative Commons license, and indicate if changes were made. The Creative Commons Public Domain Dedication waiver (http://creativecommons.org/publicdomain/zero/1.0/) applies to the data made available in this article, unless otherwise stated. 


\section{Background}

Lower respiratory infections (LRIs) are a major cause of morbidity and mortality worldwide, especially in resource-limited settings such as Cambodia, a lower middle-income country of about 16 million individuals in southeast Asia [1]. While the lack of diagnostic microbiology facilities has limited study of LRI etiologies in Cambodia, available data suggest that Streptococcus pneumoniae, Haemophilus influenzae, Pseudomonas aeruginosa, Klebsiella pneumoniae, and Burkholderia pseudomallei are the most common etiologies of community-acquired pneumonia (CAP) in Cambodia and its neighbors [2]. Mycobacterium tuberculosis infection (TB) is also a major cause of respiratory disease in Cambodia, and the incidence of TB in 2017 (326 per 100,000 population) was among the highest in the world [3].

Co-infection with TB and bacterial pathogens has been described, particularly in populations with a high TB prevalence [4-8]. Differentiating TB from other LRIs such as bacterial pneumonia is an important clinical challenge in these settings, and inability to differentiate TB from other LRIs may result in poorer health outcomes [9-11]. In this study, we analyzed data from patients presenting with symptoms of respiratory infection at a Cambodian provincial hospital who had both mycobacterial and other bacterial testing performed to determine the prevalence and etiologies of bacterial co-infection in patients with tuberculosis.

\section{Methods}

\section{Study population, design and site}

We performed a retrospective, cross-sectional study at Kampong Cham Provincial Hospital $(\mathrm{KCPH})$ in central Cambodia, analyzing data from November 2012 through December 2013. KCPH is a 260-bed government referral hospital serving a population of nearly 2 million people situated on the Mekong river, $127 \mathrm{~km}$ by road north-east of Cambodia's capital Phnom Penh. We selected this hospital because of the TB clinical/diagnostic laboratory and diagnostic microbiology laboratory capacity supported by partners Médecins Sans Frontières France and the Diagnostic Microbiology Development Program. The hospital offers a Chest Clinic for initial triage and evaluation of patients presenting with symptoms of respiratory infection, as well as both comprehensive mycobacterial and other bacterial diagnostic capacity for sputum specimen analysis [12]. The evaluating physician determines whether patients require hospitalization or if outpatient management in the clinic is appropriate. Mycobacterial and other bacterial testing is ordered based on clinical suspicion and on local standards of care. Almost all adult sputum samples are spontaneously produced. Diagnostic testing is performed in a dedicated TB laboratory and in an adjacent bacterial microbiology laboratory. TB testing includes smear, culture using the BBL MGIT (Mycobacteria Growth Indicator Tube) Manual System (Becton Dickinson, Sparks, MD, USA) and/or Lowenstein-Jensen media, and Xpert MTB/RIF [Cepheid, Sunnyvale, CA, USA]). For bacterial testing, sputum specimens are evaluated first by Gram stain and acceptable samples are cultured onto sheep blood, chocolate, and MacConkey agars; bacteria are subsequently identified by standard laboratory procedures.

The inclusion criteria for this analysis were individuals with symptoms of respiratory infection presenting to the $\mathrm{KCPH}$ Chest Clinic who underwent mycobacterial and bacterial sputum testing within 14days of each other, and who had a sputum sample deemed acceptable for bacterial culture (few $[<10]$ epithelial cells or moderate/ high leukocytes). For this study, sputum positive for mycobacterial culture or Xpert assay was considered pulmonary TB; sputum acceptable for bacterial culture growing a potentially pathogenic (non-mycobacterial) bacterial organism was considered bacterial respiratory infection (as opposed to colonization).

\section{Data collection}

We abstracted a) results of acid-fast bacilli (AFB) stain, mycobacterial culture, and Xpert MTB/RIF assays on sputum specimens from the TB laboratory records; b) Gram stain (number of squamous epithelial cells and leukocytes) and bacterial culture on sputum specimens from the bacterial microbiology laboratory records; and c) corresponding demographic information and clinical data such as medical history and clinician interpretations of chest radiographs from the Chest Clinic records.

\section{Data analysis}

Categorical data are presented as number and proportions, and are compared using $X^{2}$ or Fisher's exact tests. Continuous data are presented as median and interquartile range, and are compared using a one-way analysis of variance (ANOVA).

\section{Ethics}

Human subjects approval was granted by the National Ethics Committee of Health Research of Cambodia and by the University of Washington Institutional Review Board. All procedures performed in studies involving human participants were in accordance with the ethical standards of the institutional and/or national research committee and with the 1964 Helsinki declaration and its later amendments or comparable ethical standards. For this type of study, formal consent is not required.

\section{Results}

One hundred and thirty-seven patients underwent both mycobacterial and bacterial sputum testing within 14 
days and had acceptable sputum samples for bacterial culture. The median age was 52 years and $54 \%$ were male (Table 1). Three percent had known HIV infection, $26 \%$ were current cigarette smokers, and $37 \%$ had previously received treatment for prior pulmonary $\mathrm{TB}$. At the time of presentation, almost all (96\%) had cough. Other common symptoms were weight loss $(66 \%)$ and shortness of breath (54\%). Hemoptysis was only reported by $20 \%$. The median duration of dyspnea, cough, chest pain, fever and weight loss ranged from 30 to 60 days whereas the median duration of hemoptysis was 10 days (data not otherwise

Table 1 Characteristics of 137 individuals with mycobacterial and bacterial sputum sample tests

\begin{tabular}{|c|c|}
\hline & Median (IQR) or N (\%) \\
\hline Age (yrs) & $52(37-64)$ \\
\hline Male & $74(54)$ \\
\hline HIV infection & $4(3)$ \\
\hline Current smoking & $35(26)$ \\
\hline Previous pulmonary TB & $51(37)$ \\
\hline \multicolumn{2}{|l|}{ Number of times TB treated ${ }^{a}$} \\
\hline 1 & $41 / 50(80)$ \\
\hline $2+$ & $10 / 50(20)$ \\
\hline \multicolumn{2}{|l|}{ Symptoms at presentation } \\
\hline Shortness of breath & $74(54)$ \\
\hline Cough & $132(96)$ \\
\hline Hemoptysis & $28(20)$ \\
\hline Chest pain & $68(50)$ \\
\hline Fever & $42(31)$ \\
\hline Weight loss & $90(66)$ \\
\hline \multicolumn{2}{|l|}{ Reported medication use at presentation } \\
\hline Antimicrobials prior to presentation & $68(50)$ \\
\hline Antibacterials & 10/68 (15) \\
\hline Anti-TB & 2/68 (3) \\
\hline Unknown & $56 / 68(82)$ \\
\hline Other medications prior to presentation & $71(52)$ \\
\hline \multicolumn{2}{|l|}{ Clinical chest $\mathrm{x}$-ray interpretation } \\
\hline Normal chest x-ray & $18(13)$ \\
\hline Cavitary lesion(s) & $14(10)$ \\
\hline Infiltrates and/or consolidation & $84(61)$ \\
\hline Fibrosis & $17(12)$ \\
\hline Bronchiectasis and/or bronchitis & $4(3)$ \\
\hline \multicolumn{2}{|c|}{ Pathogenic organisms identified in sputum sample } \\
\hline None & $50(37)$ \\
\hline TB only & $27(20)$ \\
\hline Bacteria only & $47(34)$ \\
\hline TB and bacteria & $13(9)$ \\
\hline
\end{tabular}

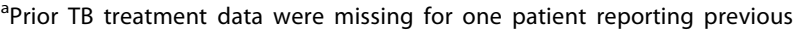
pulmonary $\mathrm{TB}$ shown). Half (50\%) reported taking antimicrobials prior to presentation. Chest radiographs at presentation were normal in only $13 \% ; 10 \%$ had one or more cavitary lesions, $61 \%$ had infiltrates and/or consolidations, $12 \%$ had fibrosis, and only $3 \%$ had bronchiectasis or bronchitis.

Sputum mycobacterial testing was positive for TB in 40 patients (29\%, Table 1); 38 patients (28\%) had growth of $M$. tuberculosis on culture, and 26 (19\%) had a positive Xpert test. None of the positive Xpert tests for M. tuberculosis was positive for rifampin resistance. Other (non-mycobacterial) bacteria were isolated from the sputum specimens of 60 patients (44\%). Thirteen patients (9\% of all patients; 33\% of TB patients) had TB and bacterial co-infection. No potentially pathogenic bacteria or TB were identified in $50 \mathrm{pa}-$ tients (37\%). Overall, clinical characteristics at presentation did not differ substantially between those with pulmonary $\mathrm{TB}$, bacterial organisms, or TB and bacterial co-infection (Table 2). A notable exception was that, in contrast to patients with other sputum test results, the majority of patients with growth of bacterial organisms had previous pulmonary TB $(N=25 / 47,53 \%)$.

Among the sixty patients with bacterial growth on sputum culture, Gram negative bacilli were the most commonly isolated organisms (Table 3). Klebsiella spp. were the most common $(N=28,20 \%)$ followed by Pseudomonas spp. $(N=20,15 \%)$. The distribution of bacterial organisms did not differ substantially between those with and without TB co-infection.

One hundred and nineteen patients $(87 \%)$ had chest radiographs that were considered abnormal by treating clinicians. The distribution of organisms identified in sputum differed across categories of chest radiographs $(p<0.001)$. Among the subset of patients with normal chest radiographs, neither bacteria nor TB were identified in the majority (13/18, 72\%) (Fig. 1). Presence of infiltrates and/or consolidations was the most common radiographic abnormality among all patients $(84 / 137,61 \%)$. Of individuals with this radiographic pattern, similar numbers had either no identified infectious etiology $(24 / 84,29 \%)$, bacterial infection $(32 / 84,38 \%)$ or TB $(23 / 84,27 \%)$. However, fewer had $\mathrm{TB}$ and bacterial co-infection $(N=5,6 \%)$. In contrast, among patients with cavitary lesions on chest radiographs, $\mathrm{TB}$ and bacterial co-infection $(6 / 14,43 \%)$ was the most common microbiological result.

\section{Discussion}

The main finding of this study is that $9 \%$ of all patients and $33 \%$ of TB patients evaluated for respiratory symptoms who underwent both mycobacterial and bacterial sputum testing at a Cambodian provincial hospital had TB and (non-mycobacterial) bacterial co-infection detected. Moreover, in this population, Klebsiella and Pseudomonas were the dominant causes of respiratory infection with and without TB co-infection. 
Table 2 Characteristics of 137 individuals with mycobacterial and bacterial sputum sample tests stratified by test results

\begin{tabular}{|c|c|c|c|c|c|}
\hline & $\begin{array}{l}\text { No identified TB or bacteria } \\
(N=50)\end{array}$ & $\begin{array}{l}\text { TB only } \\
(N=27)\end{array}$ & $\begin{array}{l}\text { Bacteria only } \\
(N=47)\end{array}$ & $\begin{array}{l}\text { TB and bacteria } \\
(N=13)\end{array}$ & $p$-value \\
\hline Age (yrs) & $55(44-64)$ & $42(32-61)$ & $53(38-65)$ & $52(45-62)$ & 0.10 \\
\hline Male & $24(48)$ & $17(63)$ & $26(55)$ & $7(54)$ & 0.65 \\
\hline HIV infection & $3(6)$ & $1(4)$ & 0 & 0 & 0.35 \\
\hline Current smoking & $11(22)$ & $9(33)$ & $9(19)$ & $6(46)$ & 0.17 \\
\hline Previous pulmonary TB & $20(40)$ & $3(11)$ & $25(53)$ & $3(23)$ & 0.002 \\
\hline Number of times TB treated ${ }^{a}$ & & & & & 0.10 \\
\hline 1 & 18/20 (90) & $1(33)$ & $20(80)$ & $2(67)$ & \\
\hline $2+$ & $2 / 20(10)$ & $2(67)$ & $5(20)$ & $1(33)$ & \\
\hline \multicolumn{6}{|l|}{ Symptoms at presentation } \\
\hline Shortness of breath & $29(58)$ & $19(70)$ & $21(45)$ & $5(38)$ & 0.11 \\
\hline Cough & $50(100)$ & $26(96)$ & $43(91)$ & $13(100)$ & 0.13 \\
\hline Hemoptysis & $6(12)$ & $4(15)$ & $15(32)$ & $3(23)$ & 0.09 \\
\hline Chest pain & $25(50)$ & $14(52)$ & $21(45)$ & $8(62)$ & 0.76 \\
\hline Fever & $12(24)$ & $13(48)$ & $13(28)$ & $4(31)$ & 0.17 \\
\hline Weight loss & $32(64)$ & $20(74)$ & $31(66)$ & $7(54)$ & 0.64 \\
\hline \multicolumn{6}{|l|}{ Reported medication use at presentation } \\
\hline Antimicrobials prior to pesentation & $25(50)$ & $18(67)$ & $19(40)$ & $6(46)$ & 0.18 \\
\hline Antibacterials & 2/25 (8) & $4 / 18(22)$ & $3 / 19(16)$ & $1 / 6(17)$ & - \\
\hline Anti-TB & $0 / 25(0)$ & $2 / 18(11)$ & $0 / 19(0)$ & $0 / 6(0)$ & - \\
\hline Unknown & 23/25 (92) & $12 / 18(67)$ & $16 / 19(84)$ & $5 / 6(83)$ & - \\
\hline Other medications prior to presentation & $28(56)$ & $16(59)$ & $22(47)$ & $5(38)$ & 0.51 \\
\hline
\end{tabular}

NOTE: Data reported as median (IQR) or N (\%)

${ }^{\mathrm{a} P r i o r} \mathrm{~TB}$ treatment data were missing for one patient reporting previous pulmonary TB

Table 3 Bacterial sputum culture results ${ }^{a}$

\begin{tabular}{llll}
\hline & Entire cohort & Bacteria only & TB and bacteria \\
& $N=137$ & $N=47$ & $N=13$ \\
\hline Normal flora & $77(56)$ & 0 & 0 \\
Klebsiella spp. & $28(20)$ & $22(47)$ & $6(46)$ \\
Pseudomonas spp. & $20(15)$ & $17(36)$ & $3(23)$ \\
Escherichia coli & $3(2)$ & $2(4)$ & $1(8)$ \\
Enterobacter spp. & $3(2)$ & $3(6)$ & 0 \\
Staphylococcus aureus & $3(2)$ & $3(6)$ & 0 \\
Haemophilus influenzae & $2(2)$ & $1(2)$ & $1(8)$ \\
Acinetobacter baumanii & $2(2)$ & 0 & $2(15)$ \\
Burkholderia pseudomallei & $1(1)$ & $1(2)$ & 0 \\
Burkholderia cepacia & $1(1)$ & $1(2)$ & 0 \\
Stenotrophomonas & $1(1)$ & $1(2)$ & 0 \\
maltophila & & $1(2)$ & 0 \\
Other Gram & $1(1)$ & & \\
negative bacilli & & &
\end{tabular}

a Percents add to $>100 \%$ because 5 cultures grew $>1$ organism:

1 grew B. pseudomallei + Klebsiella spp.

3 grew Klebsiella spp. + Pseudomonas spp.

1 grew Pseudomonas spp. + S. aureus
Without the appropriate diagnostic modalities, the presence of either or both $\mathrm{TB}$ and bacterial respiratory infection is often difficult to distinguish. Our findings suggest that $\mathrm{TB}$ and bacterial co-infection may be more likely among patients with cavitary lesions on chest radiography. Another study of patients with acute LRI in Cambodian provincial hospitals found that Gram negative bacteria were more likely to be cultured from patients whose chest radiographs had pulmonary sequelae of prior infections, including $\mathrm{TB}$, compared to those whose chest radiographs were normal [13]. Nonetheless, as in other studies, $[5,6,13]$ our results highlight that clinical and radiographic characteristics are insufficient to meaningfully distinguish between pulmonary $\mathrm{TB}$, bacterial infection and TB/bacterial co-infection in TB endemic regions, given overlapping presentations.

Few published data describe the burden of co-infection with TB and other pathogens in the general populations of regions where TB prevalence is high and TB treatment is commonly based on presumptive diagnoses [5-8]. For instance, in Kenya, $\sim 8 \%$ of patients hospitalized with CAP had TB and bacterial co-infection [8]. In the same Cambodian hospital as our study, nearly $11 \%$ of patients with suspected pulmonary TB had growth of 


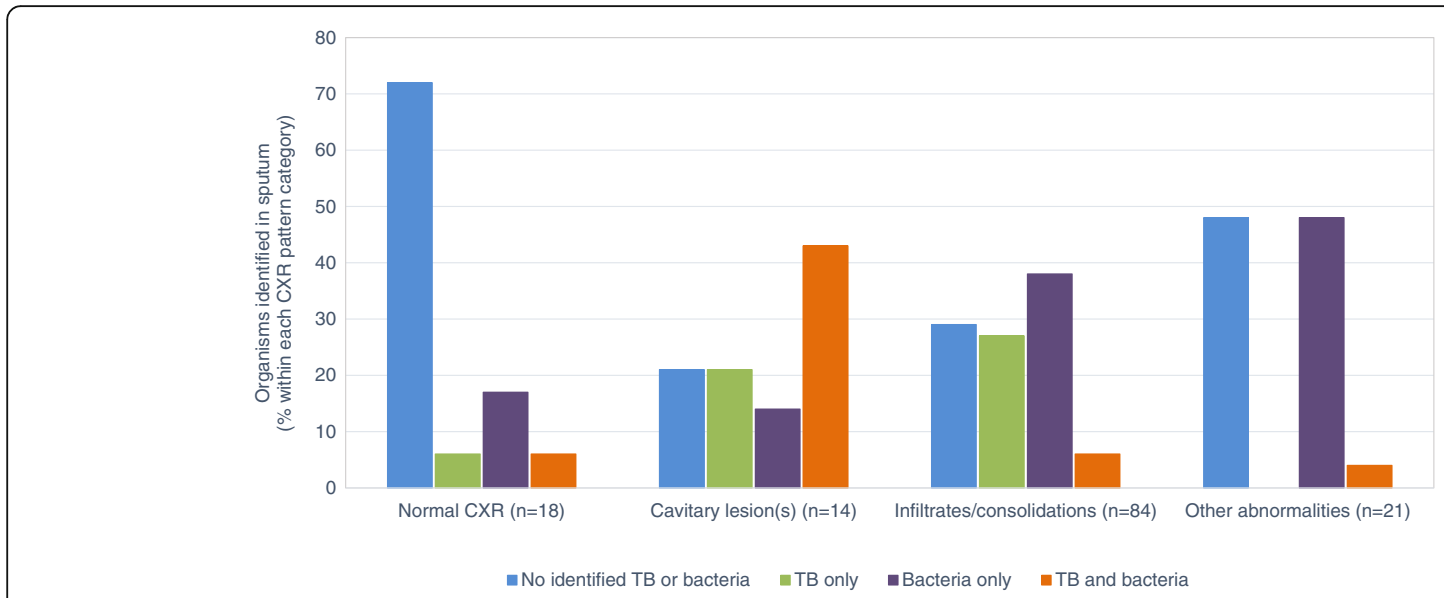

Fig. 1 Organisms identified in sputum stratified by chest radiograph findings. The exact test $p$-value comparing types of identified organisms in the sputum (TB and/or bacteria) across categories of chest radiograph findings was $<0.001$. The "Other abnormalities" category comprises fibrosis, bronchiectasis, and bronchitis

non-tuberculous mycobacterial isolates on sputum culture, and 4 of 217 patients with pulmonary TB were also diagnosed with non-tuberculous mycobacterial pulmonary disease [12]. Our study provides further evidence that co-infection of other respiratory pathogens with $\mathrm{TB}$ is readily quantifiable, although the high rate of co-infection observed in TB-infected individuals (33\%) may overestimate the true prevalence in all TB patients at this hospital. We only included patients in this study with sputum specimens that were tested for both mycobacterial and bacterial pathogens; yet, for the majority of patients presenting to the hospital with respiratory symptoms sputum samples are tested for $\mathrm{TB}$ alone. The patients we studied may therefore have been more likely to have had sequelae related to prior TB, non-resolving infection, immune compromise, or bronchiectasis.

Over half of the patients in our study were taking antimicrobials and other medications prior to presentation, raising concern that culture results may have been falsely negative or that underlying chronic comorbidities may play a role in LRI in resource-limited settings as has been found in higher resource countries [14]. It remains unknown whether pulmonary TB infection increases the risk of bacterial super-infection or whether acute presentation of pulmonary TB is precipitated by development of bacterial pneumonia. Regardless, misdiagnosis of either TB or other bacterial pulmonary infection has the potential to lead to poorer outcomes, including increased healthcare costs, antimicrobial resistance and mortality [9-11].

Our finding that Gram negative bacteria, including Klebsiella and Pseudomonas, are the most common pathogens identified among the patients in this study is consistent with published data highlighting the incidence and prevalence of bacterial CAP in Cambodia and neighboring countries [2, 15]. Furthermore, we did not identify any cases of $S$. pneumoniae infection in this study. The lack of $S$. pneumoniae and the relative abundance of Gram negative bacteria cultured from respiratory specimens may be due to antibiotic pre-treatment in our population. Gram negative bacteria cultured from sputum may also reflect colonization of abnormal lung architecture following previous $\mathrm{TB}$ or respiratory infection $[16,17]$. Alternatively, this may represent a troubling epidemiologic transition of sorts - the review by Goyet et al. found that $S$. pneumoniae was frequently identified in earlier studies, but Gram negative bacteria were consistently identified more frequently among adults hospitalized with bacterial CAP during more recent studies [2]. Alarmingly, this trend may not be isolated to southeast Asia. Gram negative bacteria were isolated from nearly half of Nigerian TB patients receiving anti-TB therapy who presented with acute LRI [6].

An important strength of this study was our access to advanced, high-quality TB and microbiologic diagnostic data from well-established laboratories. Furthermore, we were able to link these data to clinical information, including clinical chest radiography. Our study also had several limitations. This was a single center, retrospective analysis with a small sample, limiting power to make statistical inferences. Our analysis was restricted to the subset of patients for whom both mycobacterial and bacterial testing was ordered by treating clinicians. Our results may not be globally generalizable, but, importantly, studies from the same region have identified similar bacterial pathogens in CAP. Samples were not analyzed for viral pathogens, which may have accounted for some 
instances in which chest radiography was abnormal but neither bacterial nor mycobacterial pathogens were identified. Additionally, positive bacterial sputum cultures could well represent colonization rather than true infection, especially among those with evidence of underlying chronic lung disease. We also could not distinguish between bronchiectasis exacerbations and pneumonia. HIV infection is a major risk factor for TB and HIV co-infection alters the presentation and outcome of $\mathrm{TB}$, yet HIV infection in our study may have been under-reported. We did not have access to details of clinical treatment outcomes. Further, prospective studies are needed to address these limitations.

\section{Conclusions}

Among patients with presumptive LRI who underwent mycobacterial and bacterial sputum testing, $9 \%$ of all patients and $33 \%$ of TB patients had TB and other bacterial co-infection. Klebsiella and Pseudomonas were the dominant bacterial pathogens cultured regardless of $\mathrm{TB}$ co-infection. Increasing the availability of resources for microbiologic diagnostics for pulmonary $\mathrm{TB}$ and bacterial pneumonia is critical to ensure appropriate administration of antimicrobial agents in this era of expanding antimicrobial resistance among mycobacterial and bacterial pathogens.

\section{Abbreviations}

AFB: Acid-fast bacilli; ANOVA: One-way analysis of variance; CAP: Communityacquired pneumonia; KCPH: Kampong Cham Provincial Hospital; LRI: Lower respiratory infection; MGIT: Mycobacteria Growth Indicator Tube; TB: Mycobacterium tuberculosis infection/tuberculosis

\section{Acknowledgments}

We thank staff and patients at Kampong Cham Provincial Hospital, and Bettina Poepping, Julie Papango, Jean-Philippe Dousset, and Olivier Camelique for facilitating the study.

\section{Funding}

Funding was provided by the Firland Foundation and by the University of Washington International Respiratory and Severe Illness Center (INTERSECT). The funders played no role in the design of the study, in collection, analysis, and interpretation of data, or in writing the manuscript.

\section{Availability of data and materials}

The datasets generated and analyzed during this study are available from the corresponding author on reasonable request.

\section{Authors' contributions \\ Conception, design, and implementation of study: YP, SN, BB, ST, SY, CK, JL, TF, SC, TEW. Acquisition of data: YP, SN, CS, BB, DP, HN, RN. Analysis and interpretation of data: EFA, YP, TEW. Drafting manuscript: EFA, TEW. Revising manuscript critically for intellectual content: All authors. All authors have read and approved the manuscript.}

\section{Ethics approval and consent to participate}

Human subjects approval was granted by the National Ethics Committee of Health Research of Cambodia and by the University of Washington Institutional Review Board. All procedures performed in studies involving human participants were in accordance with the ethical standards of the institutional and/or national research committee and with the 1964 Helsinki declaration and its later amendments or comparable ethical standards. For this type of study, formal consent is not required.
Consent for publication

Not applicable

\section{Competing interests}

EFA has received research grants from the US National Institutes of Health and the Thrasher Research Fund. TEW has received research grants from the US National Institutes of Health, the Firland Foundation, the Doris Duke Charitable Foundation, and the US Defense Threat Reduction Agency.

\section{Publisher's Note}

Springer Nature remains neutral with regard to jurisdictional claims in published maps and institutional affiliations.

\section{Author details}

${ }^{1}$ International Respiratory and Severe IIIness Center, University of Washington, Seattle, WA, USA. ${ }^{2}$ Division of Pulmonary, Critical Care, and Sleep Medicine, Department of Medicine, University of Washington, 325 Ninth Avenue, Box 359640, Seattle, WA 98104, USA. ${ }^{3}$ Kampong Cham Provincial Hospital, Kampong Cham, Cambodia. ${ }^{4}$ University of Washington Medical Center and Department of Global Health, University of Washington, Seattle, WA, USA. ${ }^{5}$ Médecins Sans Frontières France, Kampong Cham,

Cambodia. ${ }^{6}$ Diagnostic Microbiology Development Program, Phnom Penh, Cambodia. ${ }^{7}$ University of Health Sciences, Phnom Penh, Cambodia.

${ }^{8}$ Calmette Hospital, Phnom Penh, Cambodia.

Received: 20 November 2018 Accepted: 3 March 2019

Published online: 11 March 2019

\section{References}

1. GBD 2016 Lower Respiratory Infections Collaborators. Estimates of the global, regional, and national morbidity, mortality, and aetiologies of lower respiratory infections in 195 countries, 1990-2016: a systematic analysis for the global burden of disease study 2016. Lancet Infect Dis. 2018;18(11):1191-210.

2. Goyet S, Vlieghe E, Kumar V, Newell S, Moore CE, Bousfield R, et al. Etiologies and resistance profiles of bacterial community-acquired pneumonia in Cambodian and neighboring countries' health care settings: a systematic review (1995 to 2012). PLoS One. 2014;9(3):e89637.

3. Chen LX. Excited state molecular structure determination in disordered media using laser pump/X-ray probe time-domain X-ray absorption spectroscopy. Faraday Discuss. 2003;122:315-29 discussion 81-93.

4. Schleicher GK, Feldman C. Dual infection with Streptococcus pneumoniae and mycobacterium tuberculosis in HIV-seropositive patients with community acquired pneumonia. Int J Tuberc Lung Dis. 2003;7(12):1207-8.

5. Moore DP, Klugman KP, Madhi SA. Role of Streptococcus pneumoniae in hospitalization for acute community-acquired pneumonia associated with culture-confirmed mycobacterium tuberculosis in children: a pneumococcal conjugate vaccine probe study. Pediatr Infect Dis J. 2010;29(12):1099-104.

6. Iliyasu G, Mohammad AB, Yakasai AM, Dayyab FM, Oduh J, Habib AG. Gramnegative bacilli are a major cause of secondary pneumonia in patients with pulmonary tuberculosis: evidence from a cross-sectional study in a tertiary hospital in Nigeria. Trans R Soc Trop Med Hyg. 2018;112(5):252-4.

7. Vidyalakshmi K, Chakrapani M, Shrikala B, Damodar S, Lipika S, Vishal S. Tuberculosis mimicked by melioidosis. Int J Tuberc Lung Dis. 2008;12(10): 1209-15.

8. Scott JA, Hall AJ, Muyodi C, Lowe B, Ross M, Chohan B, et al. Aetiology, outcome, and risk factors for mortality among adults with acute pneumonia in Kenya. Lancet. 2000;355(9211):1225-30.

9. Chen TC, Lu PL, Lin CY, Lin WR, Chen YH. Fluoroquinolones are associated with delayed treatment and resistance in tuberculosis: a systematic review and meta-analysis. Int J Infect Dis. 2011;15(3):e211-6.

10. Shimazaki T, Taniguchi T, Saludar NRD, Gustilo LM, Kato T, Furumoto A, et al. Bacterial co-infection and early mortality among pulmonary tuberculosis patients in Manila, the Philippines. Int J Tuberc Lung Dis. 2018;22(1):65-72.

11. van der Heijden YF, Maruri F, Blackman A, Holt E, Warkentin JV, Shepherd $\mathrm{BE}$, et al. Fluoroquinolone exposure prior to tuberculosis diagnosis is associated with an increased risk of death. Int J Tuberc Lung Dis. 2012; 16(9):1162-7.

12. Bonnet M, San KC, Pho Y, Sok C, Dousset JP, Brant W, et al. Nontuberculous mycobacteria Infections at a provincial reference hospital, Cambodia. Emerg Infect Dis. 2017;23(7):1139-47. 
13. Rammaert B, Goyet S, Tarantola A, Hem S, Rith S, Cheng S, et al. Acute lower respiratory infections on lung sequelae in Cambodia, a neglected disease in highly tuberculosis-endemic country. Respir Med. 2013;107(10): 1625-32.

14. Singh K, Patel SA, Biswas S, Shivashankar R, Kondal D, Ajay VS, et al. Multimorbidity in south Asian adults: prevalence, risk factors and mortality. J Public Health (Oxf). 2018. https://doi.org/10.1093/pubmed/fdy017 [Epub ahead of print].

15. Inghammar M, Borand L, Goyet S, Rammaert B, Te V, Lorn Try P, et al. Community-acquired pneumonia and gram-negative bacilli in Cambodiaincidence, risk factors and clinical characteristics. Trans R Soc Trop Med Hyg. 2018;112(2):57-63.

16. Chakaya J, Kirenga B, Getahun H. Long term complications after completion of pulmonary tuberculosis treatment: a quest for a public health approach. J Clin Tuberc Other Mycobact Dis. 2016:3:10-2.

17. Pasipanodya JG, Miller TL, Vecino M, Munguia G, Garmon R, Bae S, et al. Pulmonary impairment after tuberculosis. Chest. 2007:131(6):1817-24.

Ready to submit your research? Choose BMC and benefit from:

- fast, convenient online submission

- thorough peer review by experienced researchers in your field

- rapid publication on acceptance

- support for research data, including large and complex data types

- gold Open Access which fosters wider collaboration and increased citations

- maximum visibility for your research: over $100 \mathrm{M}$ website views per year

At BMC, research is always in progress.

Learn more biomedcentral.com/submissions 